\title{
(6) OPEN ACCESS \\ Identification of the severe sepsis patient at triage: a prospective analysis of the Australasian Triage Scale
}

\author{
Diane J Chamberlain, Eileen Willis, Robyn Clark, Genevieve Brideson
}

Faculty of Medicine, Nursing and Health Sciences, Flinders University, Adelaide, South Australia, Australia

\section{Correspondence to} Dr Diane J Chamberlain, Faculty of Medicine, Nursing and Health Sciences, Flinders University, GPO, Box 2100,

Adelaide, South Australia

5001, Australia;

di.chamberlain@flinders.edu.au

Received 4 May 2014 Revised 23 October 2014 Accepted 16 November 2014 Published Online First 11 December 2014

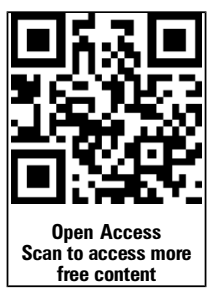

\section{ABSTRACT}

Objective This study aims to investigate the accuracy and validity of the Australasian Triage Scale (ATS) as a tool to identify and manage in a timely manner the deteriorating patient with severe sepsis.

Methods This was a prospective observational study conducted in five sites of adult patients. Keywords and physiological vital signs data from triage documentation were analysed for the 'identified' status compared with confirmed diagnosis of severe sepsis after admission to the intensive care unit. The primary outcome is the accuracy and validity of the ATS Triage scale categories to identify a prespecified severe sepsis population at triage. Secondary outcome measures included time compliance, antimicrobial administration and mortality prediction. Statistical analysis included parameters of diagnostic performance. Adjusted multivariate logistic regression analysis was applied to mortality prediction. Results of 1022 patients meeting the criteria for severe sepsis, 995 were triaged through the emergency department, 164 with shock. Only $53 \%(n=534)$ were identified at triage. The overall sensitivity of the ATS to identify severe sepsis was $71 \%$. ATS 3 was the most accurate (likelihood ratio positive, 2.45 , positive predictive value 0.73 ) and ATS 2 the most valid (area under the curve 0.567$)$ category. Identified cases were more likely to survive (OR $0.81,95 \% \mathrm{Cl} 0.697$ to 0.94 , $\mathrm{p}<0.007)$. The strongest bias-adjusted predictors of mortality were circulatory compromise variable (1.78, $95 \% \mathrm{Cl} 1.34$ to $1.41, \mathrm{p}<0.001$ ), lactate $>4$ (OR 1.63, $95 \% \mathrm{Cl} 1.10$ to $2.89, \mathrm{p}<0.001)$ and ATS 1 category (OR $1.55,95 \% \mathrm{Cl} 1.09$ to $2.35, \mathrm{p}<0.005$ ).

Conclusions The ATS and its categories is a sensitive and moderately accurate and valid tool for identifying severe sepsis in a predetermined group, but lacks clinical efficacy and safety without further education or quality improvement strategies targeted to the identification of severe sepsis.

\section{INTRODUCTION}

Severe sepsis is defined as the systemic inflammatory response (SIRS) to infection plus sepsis-induced organ dysfunction or tissue hypo-perfusion. ${ }^{1}$ It remains a major cause of morbidity and mortality globally with a $20 \%-30 \%$ mortality rate. ${ }^{2}$ The identification of severe sepsis relies on the presenting pattern of physiological vital signs, symptoms and history related to infection, SIRS response and organ failure. ${ }^{3}$ Fever is often the first presenting abnormality in approximately $40 \%$ of patients. $^{245}$ Pneumonia infections are the most common with genitourinary infections the most common

\section{Key messages}

What is already known on this subject

- Patients with severe sepsis represent the population at the greatest risk of unchecked deterioration in our healthcare systems.

- Triage to the emergency department is the most critical time in the identification of evolving severe sepsis.

- Poor identification impacts on patient survival and the ability to implement appropriate resuscitation measures.

What this study adds

- The Australasian Triage Scale (ATS) is comprised of descriptors that match the consensus criteria for severe sepsis.

- The accuracy and validity of the ATS categories to identify severe sepsis were moderate in a predetermined cohort of severe sepsis patients.

- There was moderate agreement between those identified at triage in the emergency department and confirmed diagnosis of severe sepsis in the intensive care unit.

- Circulatory compromise as described in ATS 2 and elevated lactate were the strongest predictors of inhospital mortality.

- Patients who were identified with severe sepsis at triage were more likely to survive.

presentation in older persons. The absence of fever and presence of sepsis-induced hypothermia are more likely in patients at the extremes of age, debilitated patients, those with chronic alcohol, liver and renal disease. ${ }^{5}{ }^{6}$ Withdrawal and agitation can be subtle and may be the sole presentations of sepsis in the elderly. ${ }^{2}$ Patients with severe sepsis represent the population at the greatest risk of unchecked deterioration in our healthcare systems. ${ }^{4-6}$ The challenges in reliably identifying severe sepsis on clinical presentation remain the greatest barrier to implementing any guidelines, ${ }^{7}$ institutional protocols ${ }^{8}{ }^{9}$ or toolkits ${ }^{10}$ developed to reduce mortality.

Triage to the emergency department (ED) is the most critical time in the identification of evolving severe sepsis and is the first part of a differential diagnosis. Therefore, it is essential that any tool or scale designed to assist allows for a rapid and reliable identification. Then, early resuscitation interventions can be implemented, including antimicrobial therapy within the first hour. ${ }^{11} 12$ 
The Australasian Triage Scale (ATS) consists of five tiers that link patient history and physiological vital signs and symptoms to clinical urgency and the maximum time that patients should wait. ${ }^{13}$ The most urgent clinical feature determines the ATS category, with consideration of the presenting history, features, age and comorbidities. ATS category 1 requires immediate attention and ATS category 2 has a maximum waiting time of $10 \mathrm{~min}$. The clinical descriptors provide a guide to each category and are similar to the physiological vital signs and symptoms included in the consensus definition of severe sepsis ${ }^{1}$ and may assist in its identification at triage as described in tables 1 and 2 .

The triage characteristics of patients with infection were described by Fry et $a l,{ }^{14}$ where less urgent triage codes were allocated to patients with infection compared with patients with non-infective conditions. While allocating a lower urgency code may have been clinically reasonable, there was evidence to suggest that sepsis mortality rate was impacted due to poor identification.

In 2010, Tromp et $a l^{15}$ reported that $65 \%$ of ED patients were accurately identified and diagnosed by the triage nurses compared with confirmed discharge data. This was after an education programme in phase II of the study. Yet, there was no triage tool or scale reported or validated in the study.
Many studies examining compliance with the severe sepsis guidelines, bundles or protocols in the ED report difficulties in the identification of severe sepsis. ${ }^{16-18}$ Still, there was no reference to which triage tools or scales were used to identify the condition. Accordingly, the validation of an identification system that would remain accurate when applied to patients with severe sepsis at the time of ED presentation is of high priority for both bedside clinical care and clinical research trials.

Therefore, the aim of this study was to determine the accuracy and validity of the ATS to appropriately identify and manage in a timely manner the deteriorating patient with severe sepsis including the administration of antimicrobial therapy.

\section{METHODS}

This study was a secondary analysis of a larger prospective observational study conducted in five sites investigating compliance with the sepsis guidelines. All adult sepsis patients triaged in the ED and consecutively admitted to the intensive care unit (ICU) of a participating site and meeting the consensus criteria ${ }^{1}$ for severe sepsis on ICU admission were included. Less than $24 \mathrm{~h}$ stay in the ICU, paediatric cases and readmissions were excluded. Patients were followed up until hospital discharge or death for inhospital mortality data.

Table 1 The ATS categories, MWT and ATS clinical descriptors that match descriptors of the consensus definition of severe sepsis

ATS category and MWT
ATS 1:
immediately life-threatening-
MWT nil
requires immediate attention
ATS 2:
imminently life-threatening-
MWT 10 min
important time-critical treatment or very severe
pain deteriorating rapidly

important time-critical treat
pain deteriorating rapidly

ATS 3:

potentially life-threatening or important time-critical treatment or severe pain, deterioration noted MWT $30 \mathrm{~min}$

ATS 4: potentially life-serious or situational urgency or significant complexity MWT 60 min

ATS 5: less urgent. MWT 125 min
ATS clinical descriptors that match the consensus definition descriptors of severe sepsis

\section{Cardiac arrest}

Respiratory arrest

Immediate risk to airway-impending arrest

$\mathrm{RR}<10 / \mathrm{min}$

Extreme respiratory distress

$\mathrm{BP}<80$ (adult) or severely shocked child/infant

Unresponsive or responds to pain only $(\mathrm{GCS}<9)$

Ongoing/prolonged seizure

Airway risk - severe stridor or drooling with distress

Severe respiratory distress

Circulatory compromise

Clammy or mottled skin, poor perfusion

$\mathrm{HR}<50$ or $>150$ (adult)

Hypotension with haemodynamic effects

Very severe pain-any cause

$\mathrm{BGL}<2 \mathrm{mmol} / \mathrm{L}$

Drowsy, decreased responsiveness any cause $(\mathrm{GCS}<13)$

Fever with signs of lethargy

Moderate shortness of breath

$\mathrm{SaO}_{2} 90 \%-95 \%$

$\mathrm{BGL}>16 \mathrm{mmol} / \mathrm{L}$

Seizure (now alert)

Any fever if immunosuppressed, for example, oncology patient, steroid Rx

Persistent vomiting

Dehydration

Moderately severe pain—any cause — requiring analgesia

Chest pain likely non-cardiac and moderate severity

Abdominal pain without high risk features-moderately severe or patient age $>65$ years

Foreign body aspiration, no respiratory distress

Difficulty swallowing, no respiratory distress

Moderate pain, some risk features

Vomiting or diarrhoea without dehydration

Swollen 'hot' joint

Non-specific abdominal pain

Minimal pain with no high risk features

Low-risk history and now asymptomatic

Minor symptoms of existing stable illness

Minor symptoms of low-risk conditions

Minor wounds—small abrasions, minor lacerations (not requiring sutures)

ATS, Australasian Triage Scale; BGL, blood glucose level; BP, systolic BP; MWT, maximum waiting time; Rx, treatment. 
Table 2 Physiological vital signs, symptoms and matching ATS clinical descriptor category for the stages of sepsis with typical keywords used for identifying severe sepsis

\begin{tabular}{|c|c|c|c|}
\hline $\begin{array}{l}\text { Stages of } \\
\text { sepsis }\end{array}$ & Physiological vital signs and symptoms & ATS category & $\begin{array}{l}\text { Typical keywords for } \\
\text { identifying* severe sepsis }\end{array}$ \\
\hline $\begin{array}{l}\text { Suspected } \\
\text { infection }\end{array}$ & $\begin{array}{l}\text { Visual inspection or presenting history and pain: } \\
\text { Cough/purulent sputum } \\
\text { Wound infection } \\
\text { Swollen hot painful joint } \\
\text { Abdominal symptoms } \\
\text { Urinary symptoms } \\
\text { Fever excluding all other causes }\end{array}$ & $\begin{array}{l}\text { ATS } 5 \\
\text { ATS } 5 \\
\text { ATS } 4 \\
\text { ATS } 3-4 \\
\text { ATS } 3-4 \\
\text { ATS } 3-5\end{array}$ & $\begin{array}{l}\text { Suspected infection-from organ or location } \\
\text { Examples include: } \\
\text { Pneumonia } \\
\text { UTI } \\
\text { Cellulitis }\end{array}$ \\
\hline SIRS syndrome & $\begin{array}{l}\text { Two or more of the following: } \\
\text { Body temperature }>38.5^{\circ} \mathrm{C} \text { or }<35.0^{\circ} \mathrm{C} \text { (ATS } 4 \text { ) ATS } 3 \text { if immunosuppressed or ATS } 2 \\
\text { if fever with lethargy } \\
\mathrm{HR}>90 \mathrm{bpm} \\
\mathrm{RR}>20 \text { breaths/min or arterial } \mathrm{CO}_{2} \text { tension }<32 \mathrm{~mm} \mathrm{Hg} \text { or need for mechanical } \\
\text { ventilation } \\
\text { White blood cell count }>12000 \text { or }<4000 / \mathrm{mm}^{3} \text { or immature forms }>10 \%\end{array}$ & $\begin{array}{l}\text { ATS } 2-4 \\
\text { ATS } 4-5 \\
\text { ATS } 23 \\
\text { Not Applicable } \\
\text { unless in referral }\end{array}$ & $\begin{array}{l}\text { Fever or hypothermia } \\
\text { HR elevated } \\
\text { RR elevated } \\
\text { From vital sign data or descriptive } \\
\text { Documentation }\end{array}$ \\
\hline Sepsis & $\begin{array}{l}\text { SIRS syndrome and documented suspicion of infection: } \\
\text { Visual inspection or presenting history and pain } \\
\text { Cough/purulent sputum } \\
\text { Wound } \\
\text { Abdominal symptoms } \\
\text { Urinary symptoms } \\
\text { Fever excluding all other causes }\end{array}$ & ATS 2-4 & $\begin{array}{l}\text { Suspected infection-from organ or location } \\
\text { Examples include: } \\
\text { Pneumonia } \\
\text { UTI } \\
\text { Cellulitis } \\
\text { Plus SIRS signs }\end{array}$ \\
\hline Severe sepsis & $\begin{array}{l}\text { Sepsis and at least one sign of organ hypo-perfusion or organ dysfunction: } \\
\text { Kidney-decreased urine output }(<0.5 \mathrm{~mL} / \mathrm{kg} \text { for at least } 1 \mathrm{~h}) \\
\text { Nervous system-abrupt change in mental status } \\
\text { Gut-decreased motility, decreased bowel sounds and anorexia } \\
\text { Blood-thrombocytopenia-bleeding and clotting issues } \\
\text { Heart and circulation-hypotension, tachycardia, mottled skin and capillary refill } \\
>3 \mathrm{~s} \\
\text { Lungs-respiratory distress } \\
\text { Skin and muscle-myalgia and mottled skin }\end{array}$ & $\begin{array}{l}\text { ATS } 4 \\
\text { ATS 2-3 } \\
\text { ATS } 3 \\
\text { ATS } 3 \\
\text { ATS } 2 \\
\text { ATS } 2 \\
\text { ATS } 2\end{array}$ & $\begin{array}{l}\text { Keywords that describe the organ dysfunction } \\
\text { Examples include } \\
\text { Nervous system: Acute onset-obtunded, } \\
\text { confused, agitated, disoriented } \\
\text { Circulation: as per signs and symptoms } \\
\text { Keywords } \\
\text { '? Sepsis' often used for '? severe sepsis' }\end{array}$ \\
\hline Septic shock & $\begin{array}{l}\text { Severe sepsis and one of: } \\
\text { Profound hypovolaemia, hypo-perfusion and hypoxia } \\
\text { Hypovolaemia does not respond to fluid resuscitation } \\
\text { Need for norepinephrine or epinephrine }<0.25 \mu \mathrm{g} / \mathrm{kg} \text { per min to maintain mean BP } \\
\text { above } 60 \mathrm{~mm} \mathrm{Hg} \text { ( }>80 \mathrm{~mm} \mathrm{Hg} \text { if previous hypertension) }\end{array}$ & $\begin{array}{l}\text { ATS 1-2 } \\
\text { ATS 1-2 } \\
\text { Not applicable } \\
\text { at triage }\end{array}$ & Shock or circulatory collapse or similar \\
\hline
\end{tabular}

ATS, Australasian Triage Scale; SIRS, systemic inflammatory response syndrome; UTI, urinary tract infection.

The study was conducted for a full year duration (20102011) to capture seasonal variations. All data were de-identified. Ethical approval was obtained from the five local institutional research ethics committees and affiliated university (106/012). Informed consent was waived on the basis that this was an epidemiological study without clinical intervention, and that patients managed in the resuscitation room and ICUs are critically ill and often incapable of fully informed consent. Patient management was not affected during the study.

\section{Identification of severe sepsis at triage classification}

Triage data were interrogated for patient history, baseline physiological vital signs, symptoms, laboratory data, narrative comments and allocated ATS category. Emergency triage personnel were blinded to the study and were experienced and consistent in the use of the ATS. Spontaneously documented keywords and physiological vital signs data from the triage notes related to the severe sepsis consensus definition ${ }^{1}$ and the International Sepsis Forum Consensus Conference guidelines on definitions of infections provided evidence of the identification of the condition. These were validated by a second researcher author. For example, the descriptors and/or physiological vital sign data of the presence of fever, and at least two of purulent sputum, cough, change in leucocyte count (from referral notes if applicable) and impaired oxygenation would be classified as identified suspected pneumonia with severe sepsis with the exclusion of other causes (see table 2 for physiological vital signs, symptoms and ATS clinical descriptor category for the stages of sepsis with typical keywords and physiological vital sign data used for the classification of identified severe sepsis). Patient cases with this documentation matching descriptors for 'fever' and/or physiological vital sign data $\left(\mathrm{ie}, 38.9^{\circ} \mathrm{C}\right)$ and 'moderate shortness of breath' were rated as 'identified' by the use of the ATS scale during the triage process. Fever or physiological vital sign data (ie, $38.9^{\circ} \mathrm{C}$ ) documented in isolation would only meet the criteria for SIRS. As described in table 2, patient cases with documentation and physiological vital sign data for SIRS (two criteria) plus suspected infection plus organ dysfunction were categorised as 'identified' with suspected severe sepsis.

\section{Outcome parameters}

The primary outcome was the diagnostic accuracy and validity of the ATS and its categories to appropriately identify severe sepsis at triage. Secondary outcome measures included appropriate triage allocation, antimicrobial administration and time compliance. Later, mortality was examined in terms of sepsis identification, categories of the ATS, antimicrobial administration and selected physiological vital sign baseline variables in the ED. 


\section{Statistical analysis}

Variables were tabulated and/or reported as mean, SD or median, IQR, or numbers and proportions as appropriate. No assumptions were made about missing data which was less than $0.5 \%$ due to the prospective method and interrogation of documented data. Difference testing between groups was performed using the two-tailed $t$ test, Mann-Whitney $U$ test, $\chi^{2}$ test and Fisher's exact test as appropriate. The correlation between two variables was described with Spearman's rank correlation coefficients and corresponding $\mathrm{p}$ values. The $\kappa$ statistic was calculated to measure the level of agreement between the confirmed diagnosis of severe sepsis in the ICU and the identification of severe sepsis at triage. We calculated sensitivity, specificity, positive predictive value, negative predictive value and probabilities for the ATS categories performance in identifying our prespecified severe sepsis population. Pretest odds were calculated from the known prevalence of patients in the ATS category. Accuracy was derived from the likelihood ratio positive $(\mathrm{LR}+)$. Diagnostic validity was related to the receiver operating curve (ROC) and the area under the curve (AUC) analysis.

For mortality prediction, all data were transformed into clinically meaningful categories for univariate and multivariate logistic regression analysis. Variables with $\mathrm{p}<0.10$ from univariate analysis were included in the backward stepwise logistic regression model that was also corrected for possible confounders such as age, Sequential Organ Failure Assessment score (SOFA) and Acute Physiology and Chronic Health Evaluation II (APACHE II) scores. Terms were removed from the model if the LR statistic had a significance level above 0.10 and terms were re-entered if the LR statistic had a significance level below 0.05. The goodness of fit was assessed by the Hosmer-Lemeshow test and discrimination by the area under the ROC using the C-statistic. A two-sided $\mathrm{p}$ value of 0.05 was considered statistically significant. All analyses were performed using Intercooled STATA V.11.0 (Stata Corporation, Texas, USA).

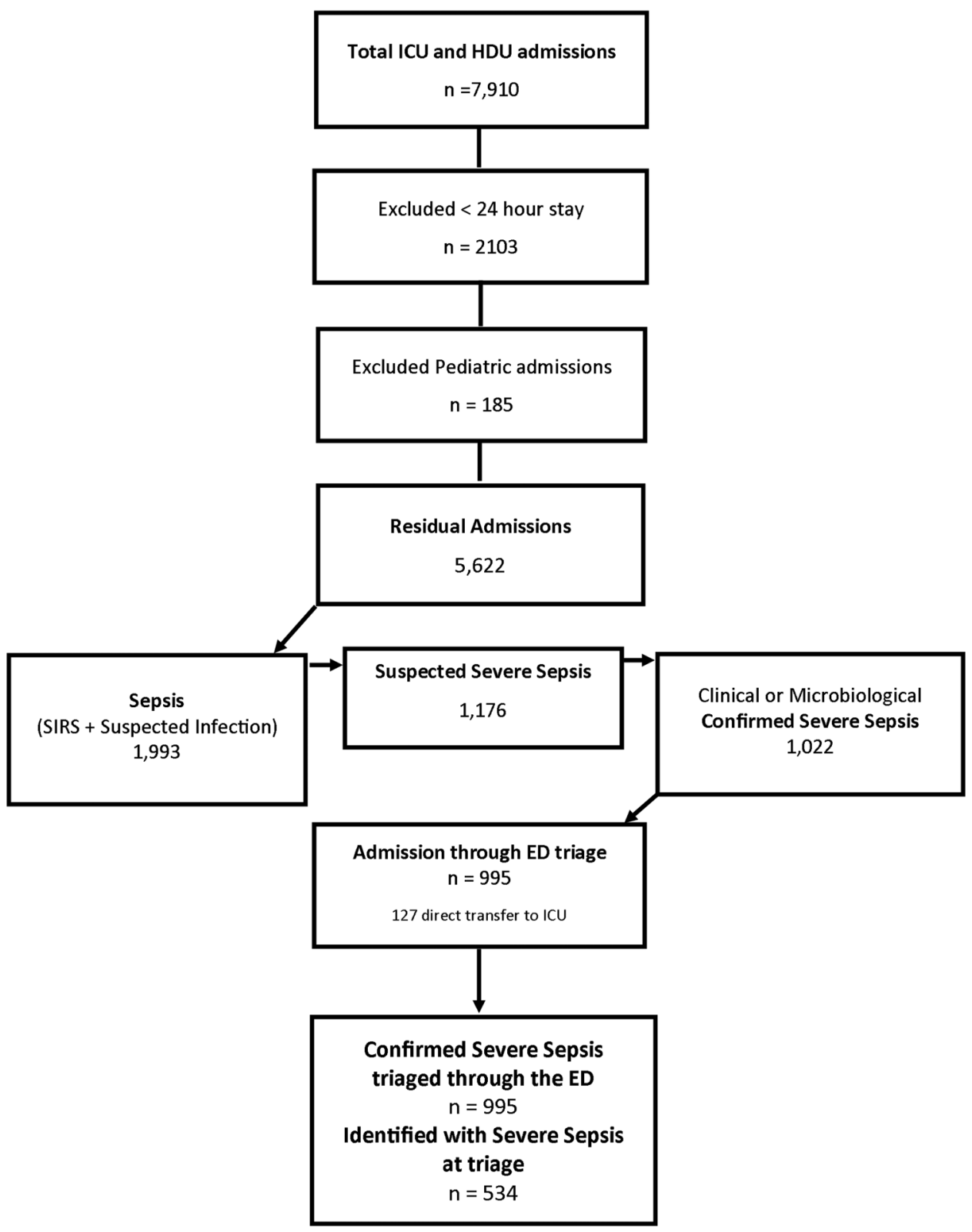

Figure 1 Cohort selection flow diagram. 


\section{RESULTS}

There were 7910 admissions to the five ICUs during the study period from the ED as described in figure 1; of these, 2103 were admissions with an uncomplicated ICU stay of less than $24 \mathrm{~h}$ and 185 paediatric admissions; both groups were excluded.

The remaining 5622 ICU admissions were screened for suspected sepsis using consensus criteria ${ }^{1}$ and 1993 (35\%) were identified as having a systemic inflammation response to a clinically suspected infection. Of these, 1176 patients were identified as having a first episode of clinically suspected severe sepsis or septic shock. Clinical- or microbiological-confirmed infection was recorded in 1022 (86.9\%). A total of 995 cases were triaged through the ED and of these cases 53\% $(n=534)$ were categorised as 'identified' severe sepsis in the ED during the triage process. The other 27 were retrieval cases admitted directly to the ICU and bypassed triage. No other tool or scale was used to identify severe sepsis (see figure 1 for the cohort selection flow diagram).

\section{Patient characteristics}

As described in table 3 , there were $8 \%$ more men (552/470), and the mean age was 57.1 years. The majority of patients had at least one comorbidity $(69 \%)$ and more than a third were obese $(35 \%)$. The lungs were the most common site of infection, accounting for $67 \%$ of infections, followed by the abdomen (23\%), with multiple cases having more than one infection site. Blood cultures were obtained in $77 \%$ with additional microbiological specimens (eg, sputum, urine) collected in $55 \%$ of patients prior to ICU admission. In all, $72 \%$ had positive microbial isolates: $52 \%$ of the positive isolates were gram-positive, $57 \%$ gram-negative and $22 \%$ fungal.
In terms of the defining features of SIRS recorded at baseline at triage (table 3), this cohort featured strongly with 59\% $(\mathrm{n}=587)$ having temperature variations either $>38$ or $<36^{\circ} \mathrm{C}$, $76 \%(\mathrm{n}=752)$ a documented HR $>90 \mathrm{bpm}$, and $32 \%(\mathrm{n}=315)$ an $\mathrm{RR} \geq 30$ breaths/min. Overall, $51 \%(\mathrm{n}=448)$ presented with an acute alteration in mental state. There were $64 \%(n=641)$ who met the criteria for 'circulatory compromise', defined in ATS category 2 as 'clammy or mottled skin, poor perfusion, $\mathrm{HR}<50$ or $>150$ and hypotension with haemodynamic effects.' Symptomatic organ failure was prevalent with respiratory, cardiac and renal dysfunction (and others) as evident by the range of signs and symptoms documented in a large proportion of cases and confirmed by a mean SOFA score of 6.1 (SD 4.0) recorded on admission to the ICU.

\section{ATS diagnostic accuracy and validity in identifying severe sepsis}

In terms of identifying severe sepsis, the ATS overall demonstrated a sensitivity of $71 \%$ and a positive predictive value of 0.586 (95\% CI 0.554 to 0.599 ) in a predetermined cohort of severe sepsis patients. Positive predictive values calculated for the ATS categories as in table 3 indicated that a positive identification made it highly likely that the patient actually did have severe sepsis. This was especially evident in ATS 2-4. Identifying accuracy was indicated by the LR + value greater than 1 and was most accurate in ATS category 3 (LR+ 2.72, $95 \%$ CI 2.50 to 2.97 ). ATS 1 and 4 were inaccurate for identifying severe sepsis (see table 4 for details). Diagnostic validity was greatest but moderate in ATS 2 (AUC $0.567,95 \%$ CI 0.528 to 0.574). Overall, the agreement between those identified at ED

Table 3 Waiting times, baseline physiological data and outcome per ATS triage category of all patients with severe sepsis at triage and ED

\begin{tabular}{|c|c|c|c|c|c|c|}
\hline Variable & ATS1 & ATS2 & ATS3 & ATS4 & ATS5 & $p$ Value \\
\hline Cases per ATS category n (\%)* & $172(17 \%)$ & $319(32 \%)$ & $258(26 \%)$ & $205(21 \%)$ & $41(4 \%)$ & 0.0516 \\
\hline Recommended MWT per ATS, minutes & 1 & 10 & 30 & 60 & 120 & - \\
\hline Actual waiting time, minutes & $5( \pm 5)$ & $24( \pm 5)$ & $36( \pm 15)$ & $68( \pm 16)$ & $148( \pm 29)$ & $<0.0001$ \\
\hline Severe sepsis identified at triage & $45(26)$ & $192(60)$ & $183(71)$ & $114(56)$ & $15(40)$ & $<0.0001$ \\
\hline Appropriate empiric antimicrobial prescriptiont & $22(13)$ & $136(43)$ & $108(42)$ & $92(45)$ & $15(40)$ & 0.9053 \\
\hline Time to first antimicrobial therapy, minutes & $128( \pm 57)$ & $109( \pm 63)$ & $136( \pm 55)$ & $182( \pm 80)$ & $197( \pm 78)$ & 0.0011 \\
\hline Lactate $>4 \mathrm{mmol}$, sepsis related & $150(87)$ & $265(83)$ & $183(71)$ & $112(55)$ & $5(13)$ & $<0.0001$ \\
\hline $\mathrm{BGL}>10 \mathrm{mmol}$ & $96(52)$ & $194(61)$ & $121(46)$ & $78(34)$ & $5(13)$ & $<0.0001$ \\
\hline Systolic BP, mm Hg & $87( \pm 17)$ & $94( \pm 17)$ & $105( \pm 25)$ & $128( \pm 32)$ & $125( \pm 35)$ & $<0.0031$ \\
\hline Circulatory compromise $\ddagger$ & $162(94)$ & $306(96)$ & $106(41)$ & $59(28)$ & $8(19)$ & $<0.0001$ \\
\hline Temperature $>38^{\circ} \mathrm{C}$ & $49(28)$ & $102(31)$ & $147(56)$ & $84(40)$ & $6(14)$ & $<0.0001$ \\
\hline Temperature $<36^{\circ} \mathrm{C}$ & $63(36)$ & $149(47)$ & $35(13)$ & $2(0.09)$ & $1(0.04)$ & $<0.0066$ \\
\hline GCS & $9( \pm 2)$ & $9( \pm 3)$ & $11( \pm 2)$ & $12( \pm 1)$ & $13( \pm 1)$ & 0.0384 \\
\hline $\mathrm{RR}>30$ breaths/min & $95(55)$ & $204(63)$ & $16(6)$ & - & - & $<0.0001$ \\
\hline $\mathrm{RR}<10$ & $43(25)$ & $8(0.02)$ & - & - & - & $<0.0001$ \\
\hline Nausea/vomiting symptoms & $123(72)$ & $187(58)$ & $74(28)$ & $81(39)$ & $20(50)$ & 0.0123 \\
\hline Pain score $>8$ & $46(26)$ & $79(25)$ & $54(21)$ & $16(8)$ & - & 0.2585 \\
\hline Mean time in $\mathrm{ED}$, hours & $1.2( \pm 0.2)$ & $3( \pm 0.2)$ & $3.8( \pm 2.7)$ & $6( \pm 2.9)$ & $10( \pm 3.6)$ & $<0.0001$ \\
\hline Mean APACHE II score (ICU) & $26( \pm 12)$ & $21( \pm 8)$ & $18( \pm 9)$ & $11( \pm 5)$ & $10( \pm 8)$ & $<0.0001$ \\
\hline Mean SOFA score (ICU) & $9( \pm 4.9)$ & $8( \pm 3.6)$ & $5( \pm 3.3)$ & $3( \pm 3.1)$ & $3( \pm 3.8)$ & 0.0103 \\
\hline Hospital mortality n (\%) & $77(45)$ & $99(31)$ & $49(9)$ & $10(5)$ & - & 0.0024 \\
\hline
\end{tabular}

Values expressed as mean \pm SD or $n(\%)$ of ATS category unless stipulated.

$\mathrm{p}$ Value $=$ differences in means and proportions at the 0.5 level.

*Includes all patients with severe sepsis.

tPrescribed and administered in the ED according to hospital guidelines.

¥Circulatory compromise: clammy or mottled skin, poor perfusion, $H R<50$ or $>150$, hypotension with haemodynamic effects.

ATS, Australasian Triage Scale; BGL, blood glucose level; ED, emergency department; ICU, measured on admission to the intensive care unit; MWT, minimum waiting time to be seen in the ED. 


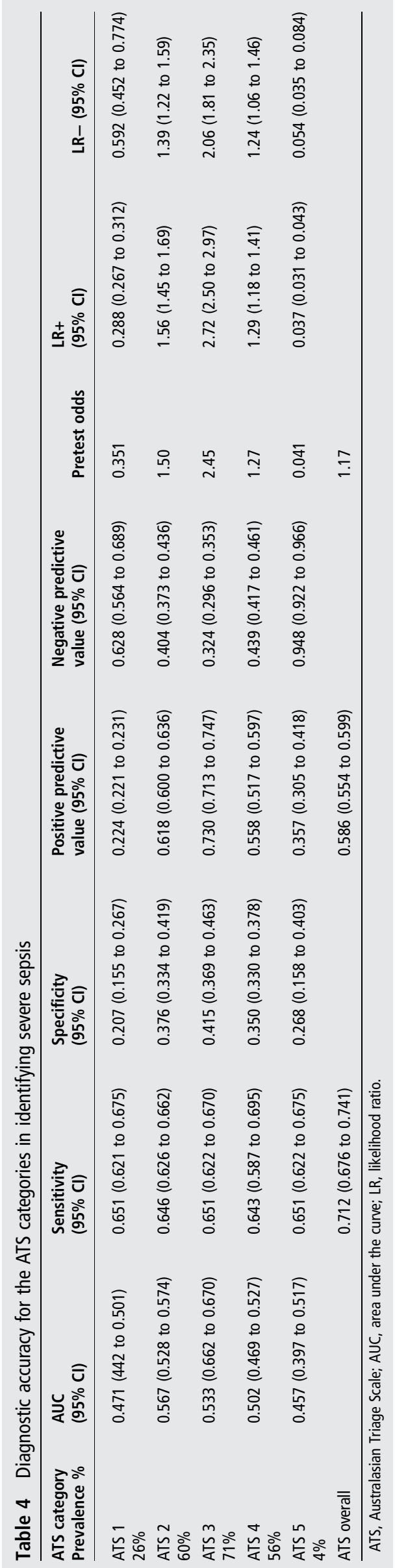

triage and the confirmed diagnosis of severe sepsis in the ICU was also moderate ( $\kappa=0.46,95 \%$ CI 0.430 to 0.496 ).

\section{Triage allocation, antimicrobial administration and time compliance}

At triage, 174 severe sepsis patients were assigned the ATS 1 category and this group were assessed immediately, remained the shortest time in the ED (mean $1.2 \mathrm{~h}, \mathrm{SD} \pm 2$ ) and had the highest APACHE II scores on admission to the ICU (mean 26, $\mathrm{SD} \pm 2)$, with the highest inhospital mortality, $(\mathrm{n}=77,45 \%)$. Overall, recommended and actual waiting times were correlated $(\mathrm{R}=0.763, \mathrm{p}<0.001)$ and compliance varied by $30 \%$.

Overall, less than half the cohort $(n=373 / 995)$ received appropriate empiric antimicrobial therapy prescription and administration in the ED. ATS 2 had the greatest compliance $(136 / 319)$ with ATS 1 the lowest compliance (22/172). The mean time to the first empiric antimicrobial therapy administration ranged from $109( \pm 63) \mathrm{min}$ for ATS 2, $128( \pm 57) \mathrm{min}$ for ATS 1, to $197( \pm 78)$ min for ATS 5 (see table 3 for detail).

\section{Sepsis identification and predictors of mortality}

Patients who were identified with severe sepsis at triage were more likely to survive (OR $0.812,95 \%$ CI 0.697 to 0.946 , $\mathrm{p}<0.007)$ than those who were not. A positive relationship was found between the increasingly urgent ATS category and inhospital mortality $\left(\chi^{2}\right.$ for trend, $\left.(4 \mathrm{df})=70.62, \mathrm{p}<0.001\right)$. ATS 1 patients had the highest mortality (OR 1.71, 95\% CI 1.21 to $2.41, \mathrm{p}=0.001)$ with ATS 5 patients all surviving. All other ATS categories were not associated with mortality in the adjusted model as described in table 5 .

The bias adjusted OR using the confounders of age, SOFA score and APACHE II score found the 'circulatory compromise' variable described in ATS 2 as 'clammy or mottled skin, poor perfusion, heart rate $<50$ or $>150 \mathrm{bpm}$ and hypotension with haemodynamic effects,' to be the strongest predictor of inhospital mortality (OR $1.78,95 \%$ CI 1.34 to $1.41, \mathrm{p}<0.001$ ), as was lactate $>4$ category (OR $1.63,95 \%$ CI 1.10 to 2.89 , $\mathrm{p}<0.001$ ) and the ATS 1 category (OR $1.55,95 \%$ CI 1.09 to $2.35, \mathrm{p}=0.005)$.

\section{DISCUSSION}

This study has evaluated the diagnostic accuracy and validity of the ATS and its categories to assist in the identification and timely management of severe sepsis in a cohort of predetermined severe sepsis patients. Overall, the ATS demonstrated a sensitivity of $71 \%$ in identifying severe sepsis. Accuracy was greatest in ATS 3 and validity in ATS 2, both of which also contained a greater number of clinical descriptors that matched the signs and symptoms of severe sepsis, most likely contributing to the degree of accuracy and validity. Agreement between the confirmed diagnoses of severe sepsis in the ICU and the identification of the syndrome at triage was moderately strong.

In reality, the ATS clinical descriptors lack prompts for suspecting infection. In contrast, organ failure hypo-perfusion or failure descriptors were more prevalent in the ATS clinical descriptors and therefore act as prompts for that component of the severe sepsis spectrum making it easier to identify. The inclusion of more infection related clinical descriptors may assist in improving the diagnostic accuracy and validity. For example, abdominal infection: pain, peritonism, respiratory infection: cough, purulent sputum, shortness of breath, neurological: altered conscious state, new onset of confusion, neck stiffness, headache, skin: wound, cellulitis, urine: dysuria, frequency, and odour. In addition, the inclusion of severe sepsis as a prompt 
Table 5 Univariate and multivariate predictors of hospital mortality

\begin{tabular}{|c|c|c|c|c|c|c|}
\hline Variable & $\begin{array}{l}\text { Univariate } \\
\text { OR }\end{array}$ & $95 \% \mathrm{Cl}$ & p Value & $\begin{array}{l}\text { Multivariate } \\
\text { OR* }^{*}\end{array}$ & $95 \% \mathrm{Cl}$ & p Value \\
\hline Total cohort & $1.00+$ & & & & & \\
\hline Temperature Fever $>38^{\circ} \mathrm{C}$ & 0.997 & 0.849 to 1.48 & 0.414 & - & - & - \\
\hline Temperature $<36^{\circ} \mathrm{C}$ & 1.24 & 0.896 to 1.73 & 0.190 & - & - & - \\
\hline $\mathrm{RR} \geq 30$ & 1.79 & 1.34 to 2.38 & $<0.001$ & 1.43 & 1.28 to 2.27 & $<0.001$ \\
\hline Nausea/vomiting & 1.74 & 0.566 to 0.963 & 0.026 & - & - & - \\
\hline Lactate $>4 \mathrm{mmol} / \mathrm{L}$ & 1.80 & 1.77 to 3.00 & $<0.001$ & 1.63 & 1.10 to 2.89 & $<0.001$ \\
\hline Circulatory compromise & 2.01 & 1.51 to 2.70 & $<0.001$ & 1.78 & 1.34 to 2.75 & $<0.001$ \\
\hline Severe sepsis identified at triage & 0.812 & 0.697 to 0.946 & 0.007 & 0.891 & 0.776 to 947 & $<0.007$ \\
\hline Not identified at triage & 1.20 & 1.05 to 1.43 & 0.007 & - & & \\
\hline ATS 1 & 1.71 & 1.21 to 2.41 & 0.002 & 1.55 & 1.09 to 2.35 & $<0.005$ \\
\hline ATS 2 & 1.04 & 0.804 to 1.35 & 0.061 & - & - & - \\
\hline ATS 3 & 0.142 & 0.103 to 0.194 & $<0.001$ & 0.167 & 0.118 to 0.245 & $<0.001$ \\
\hline ATS 4 & 0.084 & 0.061 to 0.115 & $<0.001$ & 0.088 & 0.060 to 0.118 & $<0.001$ \\
\hline Appropriate antimicrobial administration $\ddagger$ & 0.838 & 0.434 to 1.72 & 0.086 & - & & \\
\hline
\end{tabular}

No deaths registered for ATS category 5-omitted.

$\operatorname{LR} \chi^{2}(8 \mathrm{df})=219.92, \mathrm{p}<0.000$, Hosmer-Lemeshow, $\mathrm{p}=0.297$. $\mathrm{C}$ statistic $=0.776$.

${ }^{*}$ Backwards stepwise multivariate logistic regression adjusted for age, SOFA score, APACHE II score and shock.

tReference value hospital mortality $29 \%$.

\#In the emergency department.

ATS, Australasian Triage Scale at emergency department Triage; LR, Likelihood ratio.

and locating it in ATS 2 may improve the timely management of these patients.

Proportionally, only 53\% of patients were identified accurately and in clinical efficacy and safety terms this was quite low. In comparison, this was less than in the study by Tromp et al ${ }^{15}$ who after a targeted education programme identified $65 \%$ of patients with infection at triage. In this study, the remaining $47 \%$ of patients who were not identified were at greater risk of deterioration and mortality. Moreover, those identified at triage in this study were $18 \%$ more likely to survive compared with those not. This then remains an area for further educational and quality improvement development strategies.

The Clinical Excellence Commission (CEC) Sepsis Toolkit $(2013)^{10}$ states to 'use a high Australasian Triage Score (Category 1 or 2 ) to reflect the seriousness of the severe sepsis patients' condition and commencement on the sepsis pathway'. Of this cohort, $49 \%$ were allocated to ATS 1-2, with the remaining $51 \%$ being 'under triaged' according to the CEC. The current Surviving Sepsis Campaign Guidelines (SSCG) recommend administration of broad spectrum empiric intravenous antimicrobial therapy as soon as possible and within $1 \mathrm{~h}$ of diagnosing severe sepsis or septic shock. ${ }^{6}$ Results of trials indicate that there is a strong correlation between antimicrobial delay and inhospital mortality. ${ }^{12} 19$ Only $37 \%$ of our study patients received appropriate initial empiric antimicrobial therapy, and we contribute this to the time the study was conducted where the 2008 SSCG were yet to impact on clinical practice. Second, the growing organism resistance debate may have contributed to the low rates of prescription. In this study, antimicrobial therapy was not compliant with the sepsis guideline timeline. The most urgent ATS 1 category was even less compliant than the ATS 2 category, perhaps more focused on airway, breathing and circulation rather than compliance with the antimicrobial therapy timelines. Considering that the ATS is based on time frames, it underlines the need to have severe sepsis patients allocated in a higher triage category to enhance the resuscitation care and surveillance required by patients at risk of deterioration.

Inadvertently, what may have been validated in this study was the ability and accuracy of the ATS to identify hypo-perfusion.
Hypo-perfusion is prevalent in severe sepsis patients and is the most predominant contributor noted in the ATS clinical descriptors. Hypo-perfusion is well discussed in the literature but more broadly than severe sepsis including trauma. ${ }^{20-24}$ Howell et al ${ }^{20}$ reported that serum lactate was a stronger predictor of mortality and hypo-perfusion than hypotension and tachycardia in the ED. This was also evident in the study by Salottolo et $a l^{21}$ in which venous lactate was a stronger predictor of mortality compared with the Shock Index (hypotension and tachycardia) especially in the elderly patients. Also, the 2012 sepsis guidelines 'suggest targeting resuscitation to normalize lactate in patients with elevated lactate levels as a marker of tissue hypo-perfusion (grade 2C). ${ }^{6}$ In this study, the 'circulatory compromise' variable contained quite broad haemodynamic and perfusion criteria and had a stronger association with mortality than elevated lactate. Nevertheless, the measurement of venous serum lactate as a point of care test, especially in the elderly patient whose signs and symptoms often do not reflect hypo-perfusion, ${ }^{21} 22$ would be a beneficial and time efficient addition to the triage process.

\section{Limitations}

This study has several limitations. First, as this was a predetermined cohort of severe sepsis patients, the false rate of identification was not pragmatic for the ATS overall and could only be analysed in the ATS categories. We could only report the sensitivity; its effect on specificity was unknown and needs further investigation.

Second, the identification of severe sepsis relied on documented keywords and physiological vital sign data in the patient's triage notes. The urgency for resuscitation will always remain a priority to documentation; hence, the need to move urgent patient cases to a priority care may have preceded the process of documentation. Despite the careful process employed to determine the identified classification, in reality, there may have been a higher rate of identification than reported. Unavoidably, given the time spent in the ED, the patient may have deteriorated to a severe sepsis state between triage and admission to the ICU, further reducing the proportion of numbers classified as identified. Regardless of these issues, this was a five site study with a 
significant cohort and time frame and gave considerable scope to analyse the ATS and its categories as a tool for the identification and early management of the deteriorating severe sepsis patient.

\section{Summary}

Overall, the ATS was a valid and moderately accurate tool to identify severe sepsis patients especially in the ATS 2-4 categories. Despite this, clinical efficacy and safety were limited with only $53 \%$ of cases classified as identified and only $40 \%$ receiving antimicrobial therapy within the SSCG timeframes. Hypo-perfusion may have been inadvertently the variable identified as it is a predominate feature of severe sepsis. The triage process would benefit from the addition and elevation of more infection related and severe sepsis descriptors to the ATS and the point of care testing of lactate as a discriminator in suspected patients with severe sepsis.

Acknowledgements The authors thank the research assistants for multisite data collection: Tamara Hunt, Deb Rea, Justine Rivett, Wendy Corkill, Wendy Bower and Jane Wilks.

Contributors DJC conceived and designed the study, DJC and EW were involved with acquisition of data, analysis and interpretation of data. DJC and EW were involved with the drafting of the manuscript. DJC, EW, RC and GB were involved in the drafting of the work or revising it critically for important intellectual content. All authors reviewed and gave final approval of the version to be published.

Funding The Flinders Medical Centre Foundation Grant number Fmcf0910. Competing interests None.

Ethics approval Flinders Clinical Research Ethics Committee.

Provenance and peer review Not commissioned; externally peer reviewed.

Open Access This is an Open Access article distributed in accordance with the Creative Commons Attribution Non Commercial (CC BY-NC 4.0) license, which permits others to distribute, remix, adapt, build upon this work non-commercially, and license their derivative works on different terms, provided the original work is properly cited and the use is non-commercial. See: http://creativecommons.org/ licenses/by-nc/4.0/

\section{REFERENCES}

1 Levy MM, Fink MP, Marshall JC, et al. 2001 SCCM/ESICM/ACCP/ATS/SIS International Sepsis Definitions Conference. Crit Care Med 2003;31:1250-6.

2 Martin GS. Sepsis, severe sepsis and septic shock: changes in incidence, pathogens and outcomes. Expert Rev Anti Infect Ther 2012;10:701-6.

3 Perman SM, Goyal M, Gaieski DF. Initial emergency department diagnosis and management of adult patients with severe sepsis and septic shock. Scand I Trauma Resusc Emerg Med 2012;20:41.

4 Song YH, Shin TG, Kang MJ, et al. Predicting factors associated with clinical deterioration of sepsis patients with intermediate levels of serum lactate. Shock 2012:38:249-54.
5 Clinical Excellence Commission. Clinical focus report from review of root cause analysis and/or incident information management system (IIMS) data recognition and management of sepsis. Sydney: Clinical Excellence Commission, 2009.

6 Dellinger RP, Levy MM, Rhodes A, et al. Surviving sepsis campaign: international guidelines for management of severe sepsis and septic shock: 2012. Crit Care Med 2013:41:580-637.

7 Dellinger RP, Levy MM, Rhodes A, et al.; Surviving Sepsis Campaign Guidelines Committee including The Pediatric Subgroup. Surviving Sepsis Campaign: international guidelines for management of severe sepsis and septic shock, 2012. Intensive Care Med 2013;39:165-228.

8 Protocolised Management in Sepsis (ProMISe). Trial information https://www.icnarc. org/CMS/DisplayContent.aspx?root=RESEARCH (last accessed 5 May 2014).

9 Corfield AR, Lees F, Zealley I, et al. Utility of a single early warning score in patients with sepsis in the emergency department. Emerg Med J 2014;31:482-7.

10 Clinical Excellence Commission (CEC). Sepsis Toolkit, Sepsis Program Implementation Guide for NSW Healthcare Facilities. Sydney: CEC, 2013.

11 Puskarich MA, Trzeciak S, Shapiro NI, et al.; Emergency Medicine Shock Research Network (EMSHOCKNET). Association between timing of antibiotic administration and mortality from septic shock in patients treated with a quantitative resuscitation protocol. Crit Care Med 2011;39:2066-71.

12 Kumar A, Roberts D, Wood KE, et al. Duration of hypotension before initiation of effective antimicrobial therapy is the critical determinant of survival in human septic shock. Crit Care Med 2006;34:1589-96.

13 Australasian College for Emergency Medicine. Guidelines on the Implementation of the Australasian Triage Scale. 2005. http://www.acem.org.au/media/policies-andguidelines/G24-Implementation-ATS.pdf (last accessed 5 May 2014).

14 Fry M, Horvat L, Roche M, et al. The prevalence and triage characteristics of patients presenting with infection to one tertiary referral hospital. Australas Emerg Nurs J 2012;15:127-32.

15 Tromp M, Hulscher M, Bleeker-Rovers CP, et al. The role of nurses in the recognition and treatment of patients with sepsis in the emergency department: a prospective before-and-after intervention study. Int I Nurs Stud 2010;47: 1464-73.

16 Buist M, Stevens S. Patient bedside observations: What could be simpler? BMJ Quality and Safety 2013;22:699-701.

17 Hanzelka KM, Yeung S-J, Chisholm G, et al. Implementation of modified early-goal directed therapy for sepsis in the emergency center of a comprehensive cancer center. Sup Care in Cancer 2013;21:727-34.

18 Kakebeeke D, Vis A, de Deckere ER, et al. Lack of clinically evident signs of organ failure affects ED treatment of patients with severe sepsis. Int J Emerg Med 2013;6:4.

19 Gaieski DF, Mikkelsen ME, Band RA, et al. Impact of time to antibiotics on survival in patients with severe sepsis or septic shock in whom early goal-directed therapy was initiated in the emergency department. Crit Care Med 2010;38:1045-53.

20 Howell MD, Donnino M, Clardy P, et al. Occult hypoperfusion and mortality in patients with suspected infection. Intensive Care Med 2007;33:1892-9.

21 Salottolo KM, Mains CW, Offner PJ, et al. A retrospective analysis of geriatric trauma patients: venous lactate is a better predictor of mortality than traditiona vital signs. Scand I Trauma Resusc Emerg Med 2013;21:7.

22 Rogers A, Rogers F, Bradburn $\mathrm{E}$, et al. Old and undertriaged: a lethal combination. Am Surg 2012;78:711-15.

23 Martin JT, Alkhoury F, O'Connor JA, et al. 'Normal' vital signs belie occult hypoperfusion in geriatric trauma patients. Am Surg 2010;76:65-9.

24 McKenzie MS, Howell MD. Using lactate to detect occult hypoperfusion in sepsis. Int J Intensive Care 2009:16:12-15. 